\title{
Supporting Information for Catalytic Upgrading in Bacteria-Compatible Conditions via a Biocompatible Aldol Condensation
}

Dylan W. Domaille, ${ }^{1 *}$ Glenn R. Hafenstine, ${ }^{1}$ Mattias A. Greer, ${ }^{1}$ Andrew P. Goodwin, ${ }^{1,2 *}$ and Jennifer N. Cha ${ }^{1,2} *$

${ }^{1}$ Department of Chemical and Biological Engineering and ${ }^{2}$ Materials Science and Engineering Program, University of Colorado, Boulder, Boulder, CO 80303

The Supporting Information consists of 15 pages, 11 figures, and 1 table.

General procedures and methods..................................S2-S3

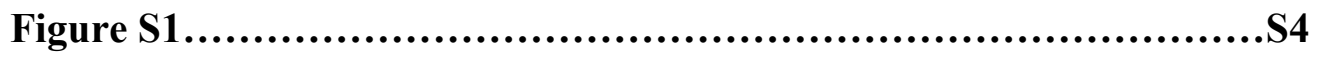

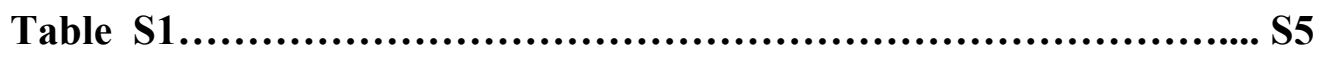

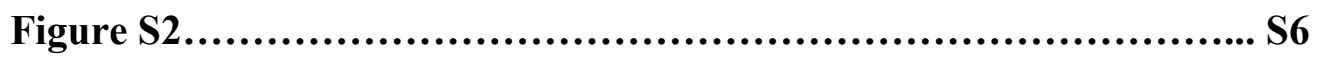

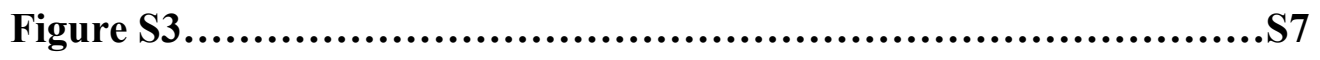

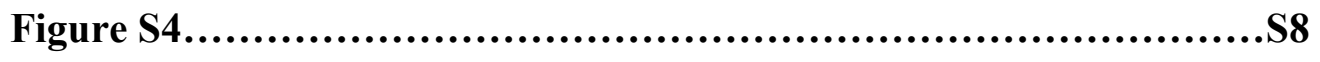

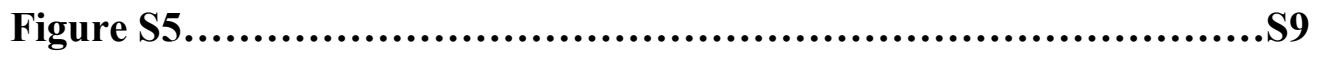

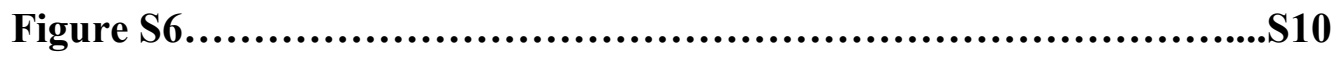

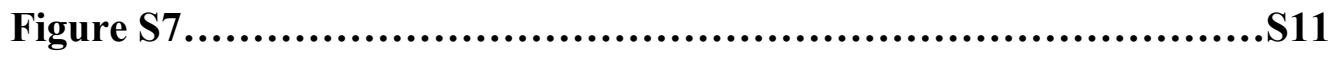

Figure S8................................................................S12

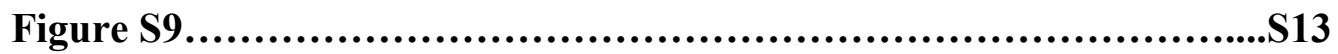

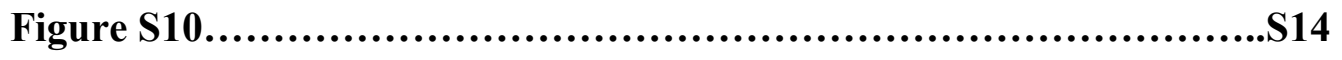

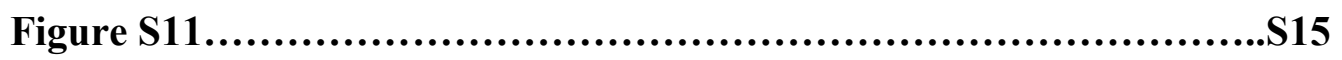




\section{General Procedures and Materials}

Unless otherwise noted, all chemicals and solvents were of analytical grade and used as received from commercial sources. Water $\left(\mathrm{dd}-\mathrm{H}_{2} \mathrm{O}\right)$ used in biological procedures or as a reaction solvent was deionized using a Milli-Q Advantage A-10 water purification system (MilliPore, USA). ${ }^{1} \mathrm{H}$ NMR spectra were acquired with a $400 \mathrm{MHz}$ Bruker AV-III spectrometer with a Sample Xpress Automatic Sample Changer. Spectra acquired in $\mathrm{CDCl}_{3}$ were referenced to residual $\mathrm{CHCl}_{3}(7.27$ ppm). Spectra were analyzed with MestreNova 8.1.4. UV-Vis spectra were acquired on a DU 730 spectrophotometer (Beckman Coulter, USA) with quartz cuvettes. Centrifugations were carried out in an X-22R benchtop centrifuge (Beckman Coulter, USA). E. coli (FDA strain Seattle 1946, ATCC 25922) was used as a cell model for establishing biocompatibility of reaction conditions.

\section{$\underline{\text { Minimal Media Preparation }}$}

Minimal Media was prepared using the following recipe:

- $5 \mathrm{~g} / \mathrm{L}$ Glucose

- $6 \mathrm{~g} / \mathrm{L} \mathrm{Na}_{2} \mathrm{HPO}_{4}$

- $3 \mathrm{~g} / \mathrm{L} \mathrm{KH}_{2} \mathrm{PO}_{4}$

- $1 \mathrm{~g} / \mathrm{L} \mathrm{NH}{ }_{4} \mathrm{Cl}$

- $500 \mathrm{mg} / \mathrm{L} \mathrm{NaCl}$

- $120 \mathrm{mg} / \mathrm{L} \mathrm{MgSO}_{4}$

- $10 \mathrm{mg} / \mathrm{L} \mathrm{CaCl}_{2}$

\section{Catalyst Screen in Minimal Media}

Solutions containing butyraldehyde $(500 \mathrm{mM})$ and catalyst $(125 \mathrm{mM})$ were in minimal media $(50$ $\mathrm{mL})$. The reactions were agitated for $24 \mathrm{~h}$ at room temperature, at which point, each reaction was extracted with dichloromethane $(45 \mathrm{~mL})$. The solvent was removed at $25^{\circ}$, the mass of material was measured, and the purity was determined using ${ }^{1} \mathrm{H}$ NMR.

\section{$\underline{\text { IC }_{50}} \underline{\text { Measurements }}$}

Catalysts: Stock solutions of each catalyst $(3200 \mathrm{mM})$ in minimal media were used to generate working catalyst concentrations of $0,3.2,10,32,100,320,1000$, and $3200 \mathrm{mM}$. An aliquot of $E$. coli stock in media ( $50 \mu \mathrm{L}$ of a $1.0 \mathrm{OD}$ stock) was added to the catalyst solution $(950 \mu \mathrm{L})$, and the reactions were shaken at $240 \mathrm{RPM}$ at $37{ }^{\circ} \mathrm{C}$ for $3 \mathrm{~h}$, at which point the reactions were immediately put on ice, and the $\mathrm{OD}_{600}$ was measured. Each reaction was prepared in triplicate. Reported values represent the mean value of three reactions, and the error bars represent standard deviation. Data were fitted to a four parameter logistic equation to extract $\mathrm{IC}_{50}$ values.

2-ethylhexenal: 2-ethylhexenal (2-EH) was prepared according to a previously published procedure. A solution of minimal media $(950 \mu \mathrm{L})$ was spiked with $2-\mathrm{EH}$ to make final concentrations of $0,0.16,0.25,0.40,0.61,1.0,1.6,2.5,4.0,6.3,10$, and $15.8 \mathrm{mM}$. An aliquot of E. coli stock $(50 \mu \mathrm{L})$ was added, and the reactions were shaken at $240 \mathrm{RPM}$ for $4.5 \mathrm{~h}$ at $37{ }^{\circ} \mathrm{C}$, at 
which point the $\mathrm{OD}_{600}$ values were measured. Data points represent the mean value of three independent values. Error bars represent standard deviation.

\section{$\underline{\text { Catalyst Efficiency at } \mathrm{IC}_{50}} \underline{\text { Concentration in Minimal Media }}$}

Stock solutions of each catalyst at its $\mathrm{IC}_{50}$ concentration and butyraldehyde $(70 \mathrm{mM} ; \sim 5 \mathrm{~g} / \mathrm{L}$ titers; $0.5 \% \mathrm{v} / \mathrm{v}$ ) were prepared in minimal media. The total reaction volume was $50 \mathrm{~mL}$. The reactions were agitated for $24 \mathrm{~h}$ at room temperature, at which point, each reaction was extracted with dichloromethane $(45 \mathrm{~mL})$. The solvent was removed at $25^{\circ}$, and the mass of the material recorded. The product purity was determined using ${ }^{1} \mathrm{H}$ NMR.

\section{Biocompatibility Measurements}

Solutions were prepared to test cell health in combinations of reaction components. The total reaction volume was $10 \mathrm{~mL}$. $\beta$-Alanine $(550 \mathrm{mM})$, glycerol tributyrate $(10 \% \mathrm{v} / \mathrm{v})$, and E. coli stock (50 $\mu \mathrm{L}$ of a 1.0 OD culture) were initially mixed with minimal media. Butyraldehyde was added every $12 \mathrm{~h}$ in $17.5 \mathrm{mM}$ aliquots over the course of $2 \mathrm{~d}$ for a final concentration of $70 \mathrm{mM}$. The reactions were agitated for 48 hours at room temperature, at which point $50 \mu \mathrm{L}$ aliquots of the aqueous phase were removed for plate assays. The organic phase of the reaction was separated by centrifugation, its mass was measured, and the product purity determined by ${ }^{1} \mathrm{H}$ NMR. The aqueous phase was extracted with dichloromethane $(15 \mathrm{~mL})$, the solvent was removed by rotary evaporation, the mass was recorded, and the composition determined by ${ }^{1} \mathrm{H}$ NMR.

\section{Plate Assay for Cell Viability}

Because solutions with glycerol tributyrate (GT) are capable of scattering light and conflating $\mathrm{OD}_{600}$ measurements, we used plate assays to calculate the number of colony forming units (CFU) per $\mathrm{mL}$ in experiments containing GT. Serial dilutions of each reaction $\left(10^{-3}, 10^{-4}, 10^{-5}\right.$, and $10^{-6}$ ) were prepared in minimal media, and $50 \mu \mathrm{L}$ of each sample was spread evenly with a sterile loop on an LB plate. The plates were incubated overnight at $37{ }^{\circ} \mathrm{C}$, and the distinct colonies were counted to obtain $\mathrm{CFU} / \mathrm{mL}$ values. 

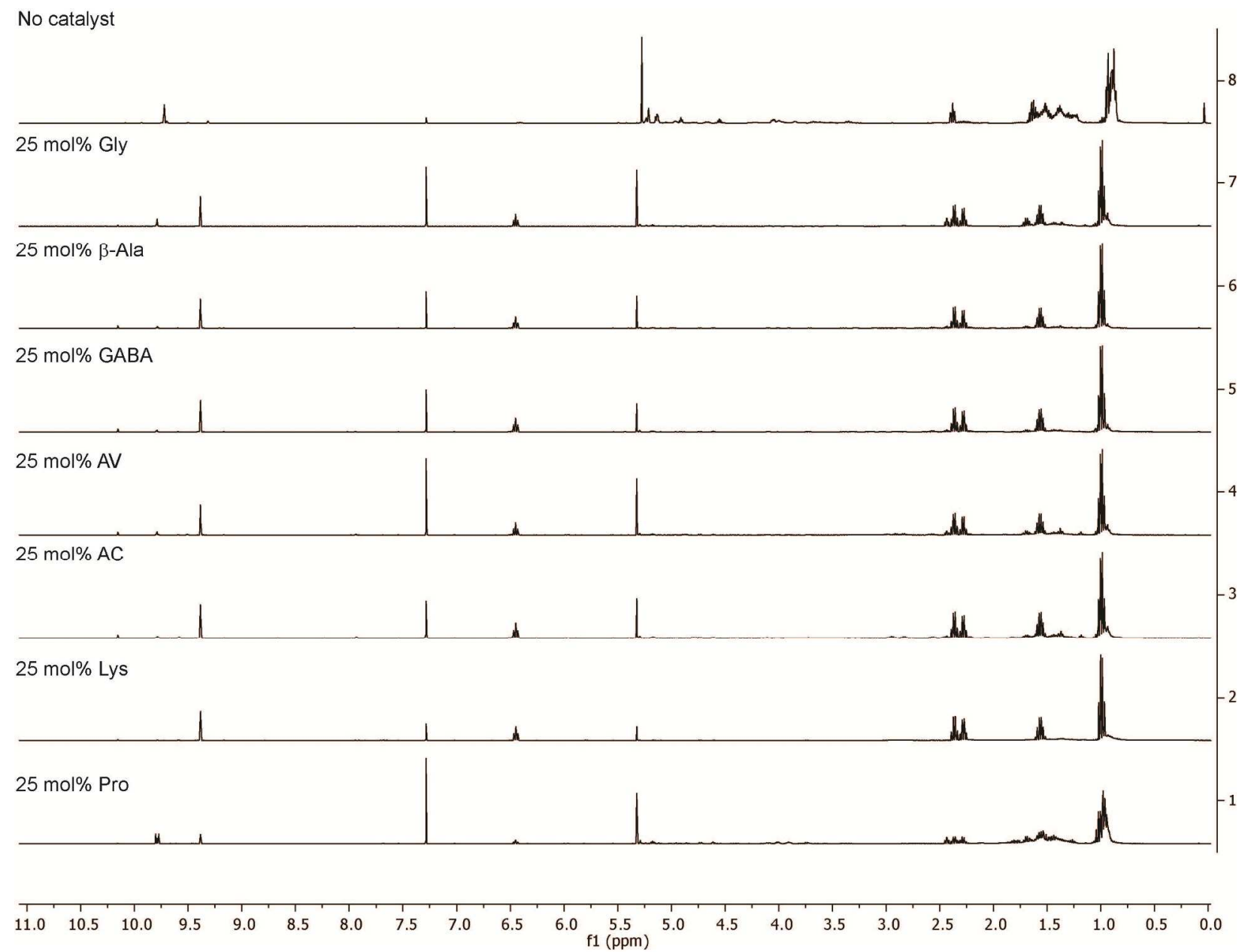

Figure S1. Compilation of NMR spectra of 2-EH generated by different amine organocatalysts. Reactions were carried out in $1 \mathrm{M}$ phosphate buffered saline (PBS) with organocatalyst (125 $\mathrm{mM})$ and butyraldehyde $(500 \mathrm{mM})$. Excellent product purity is observed for all catalysts after extraction of the aqueous media with $\mathrm{CH}_{2} \mathrm{Cl}_{2}$, except in the case of proline, which produced primarily aldol addition (not condensation) products. 
Table S1. Catalyst turnover frequencies at different catalyst and butyraldehyde concentrations. ${ }^{a}$

\begin{tabular}{cccc}
\hline Catalyst & $\begin{array}{c}\text { Catalyst } \\
\text { concentration } / \mathrm{mM}\end{array}$ & $\begin{array}{c}\text { [Butyraldehyde] } \\
\mathrm{mM}\end{array}$ & TOF h $^{-1}$ \\
\hline glycine & 170 & 70 & 0.18 \\
$\beta$-alanine & 550 & 70 & 0.06 \\
$\gamma$-aminobutyric acid & 540 & 70 & 0.16 \\
5-aminovaleric acid & 350 & 70 & 0.033 \\
6-aminocaproic acid & 540 & 70 & 0.035 \\
lysine & 40 & 70 & 1.03 \\
\hline
\end{tabular}

${ }^{\text {a }}$ Reactions $(1 \mathrm{~mL})$ were carried out at the indicated $\mathrm{IC}_{50}$ catalyst concentrations in minimal media in $\mathrm{D}_{2} \mathrm{O}$ at room temperature for $1 \mathrm{~h}$ with shaking (100 RPM). A $0.5 \mathrm{~mL}$ aliquot of each reaction was diluted with DMSO- $\mathrm{d}_{6}$ containing 15.3 mM DSS $(931 \mu \mathrm{L})$ for a final ratio of 35:65 $\mathrm{D}_{2} \mathrm{O}$ :DMSO- $\mathrm{d}_{6}$, and the TOF value was calculated based on the measured yield of 2-EH against an internal standard of DSS (10 mM final concentration). 

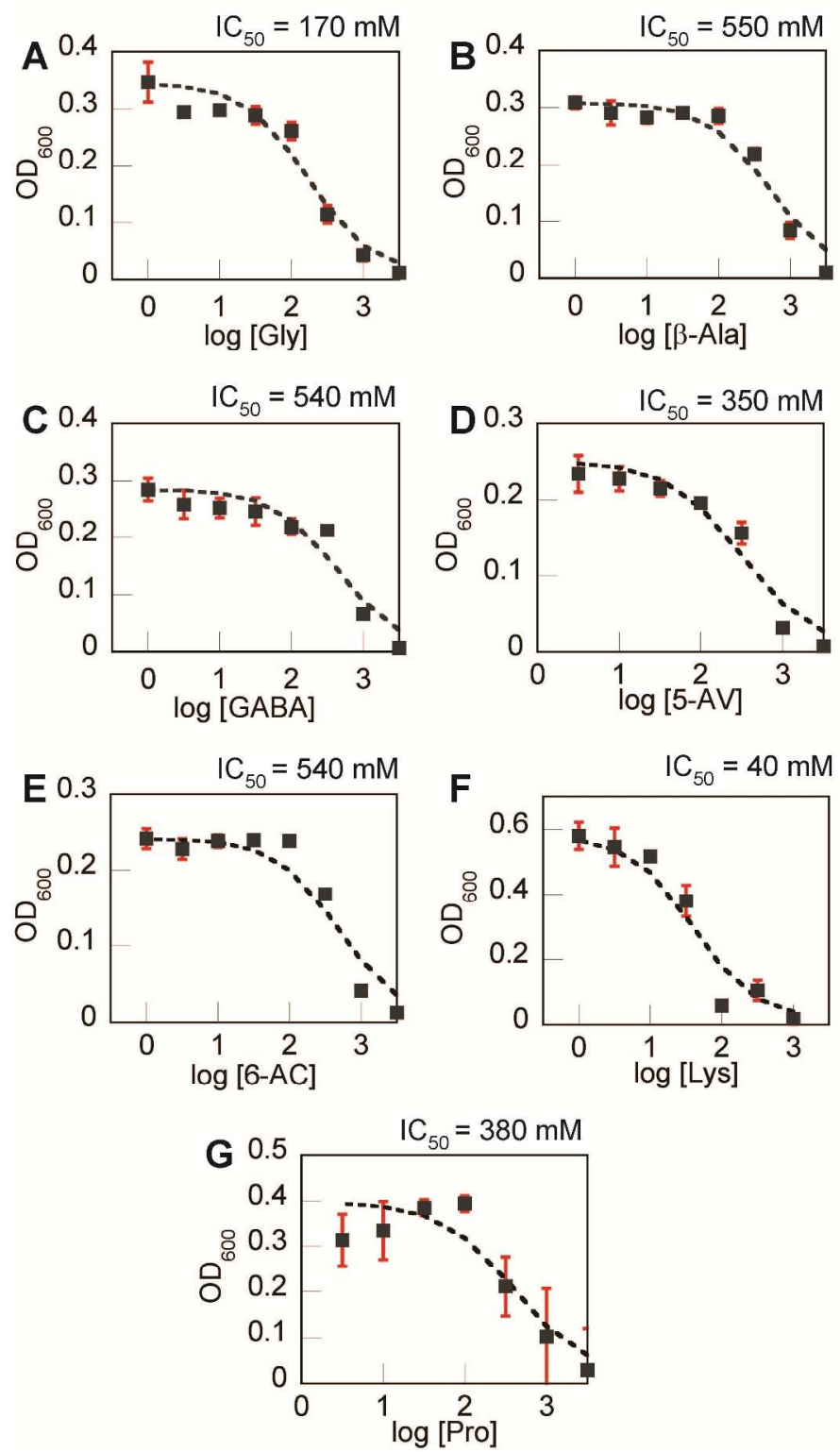

Figure S2. $\mathrm{IC}_{50}$ concentrations of (A) glycine; (B) $\beta$-alanine; (C) 4-aminobutyric acid (GABA); (D) 5-aminovaleric acid (5-AV); (E) 6-aminocaproic acid (6-AC); and (F) L-lysine. Data points represent the mean $\mathrm{OD}_{600}$ absorption of three independent experiments. Error bars represent standard deviation. Data were fitted to a four-parameter logistic function to extract $\mathrm{IC}_{50}$ values. 


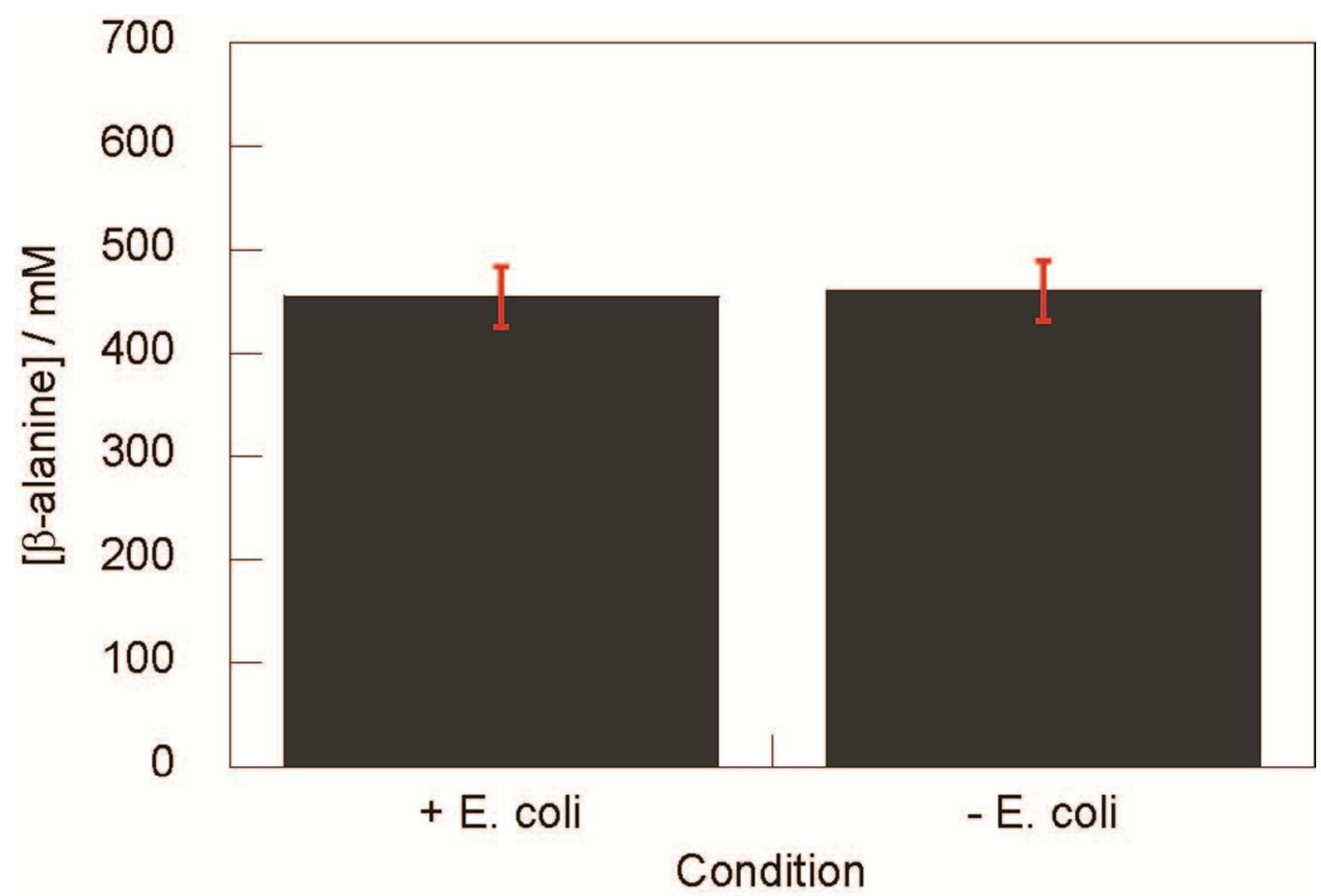

Figure S3. Samples of minimal media $(1 \mathrm{~mL})$ in $\mathrm{D}_{2} \mathrm{O}$ containing $\beta$-alanine $(540 \mathrm{mM})$ were incubated with and without $E$. coli $\left(50 \mu \mathrm{L}\right.$ of a 1.0 OD stock) and incubated at $37{ }^{\circ} \mathrm{C}$ for $24 \mathrm{~h}$. The cells were pelleted, and the solutions were spiked with the internal NMR standard 4,4dimethyl-4-silapentane-1-sulfonic acid (DSS, $250 \mu \mathrm{L}$ of a $50 \mathrm{mM}$ solution). The concentration of $\beta$-alanine was determined by ${ }^{1} \mathrm{H}$ NMR. No statistically different concentration between the samples is observed, indicating that the organocatalyst is not being consumed by E. coli or undergoing chemical reactions with media components. 


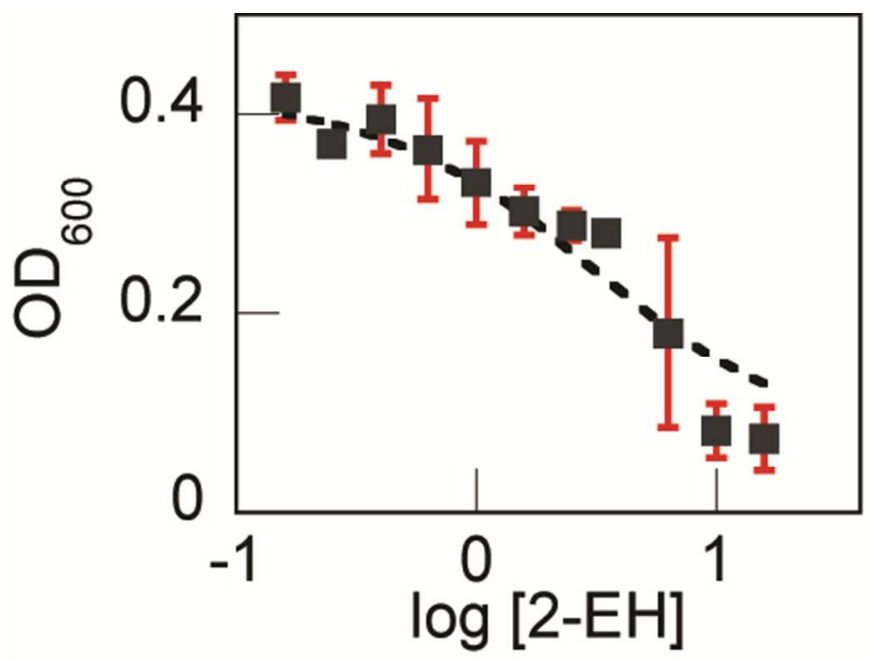

Figure S4. Toxicity of 2-ethylhexenal. Data points represent the mean $\mathrm{OD}_{600}$ absorption of three independent experiments. Error bars represent standard deviation. Data were fitted to a fourparameter logistic function to extract an $\mathrm{IC}_{50}$ value of $2.5 \mathrm{mM}$. 


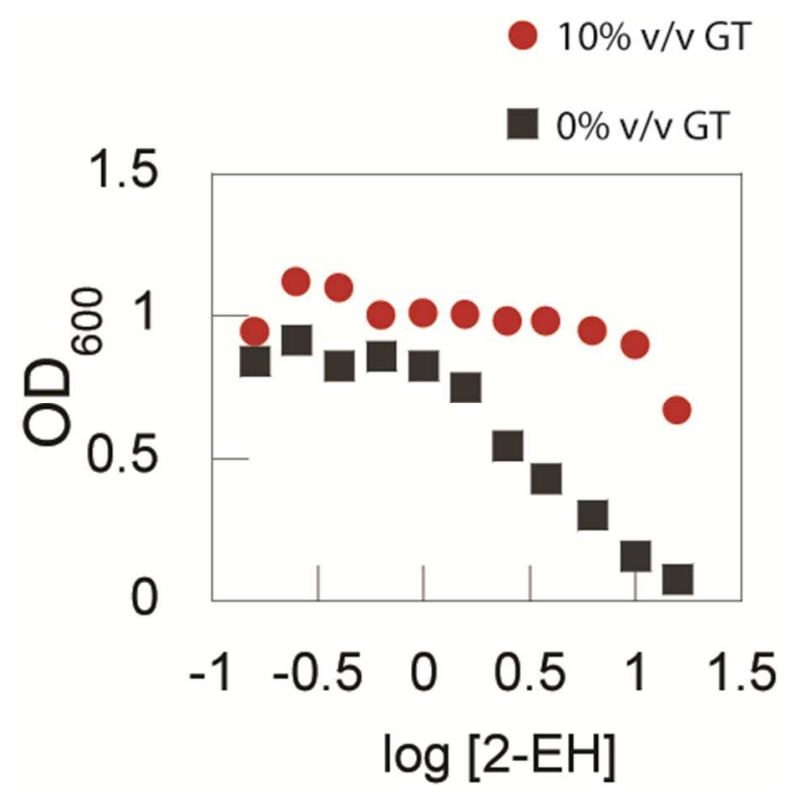

Figure S5. Effect of glycerol tributyrate on the toxicity of 2-EH. E. coli were incubated with the indicated concentrations of $2-\mathrm{EH}$ in the absence (black squares) or presence (red circles) of 10\% $\mathrm{v} / \mathrm{v}$ glycerol tributyrate. Inclusion of the glycerol tributyrate phase shifts the 2-EH $\mathrm{IC}_{50}$ to $c a$. 25 $\mathrm{mM}$. 

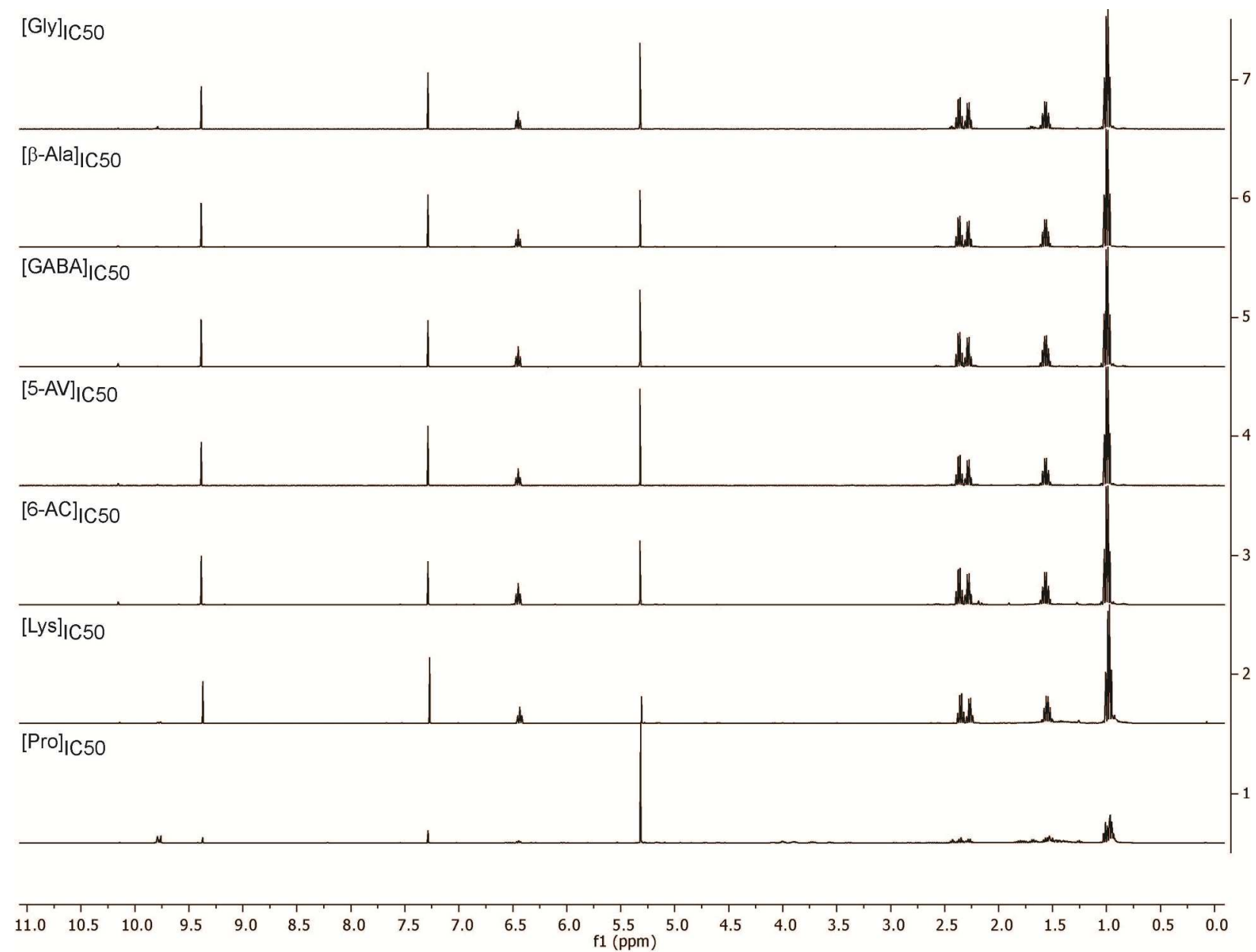

Figure S6. Compilation of NMR spectra of 2-EH generated by organocatalysts loaded at their $\mathrm{IC}_{50}$ concentrations. Reactions were carried out in minimal media with each organocatalyst loaded at their $\mathrm{IC}_{50}$ concentration with butyraldehyde $(70 \mathrm{mM} ; \sim 5 \mathrm{~g} / \mathrm{L}$ titers; $0.5 \% \mathrm{v} / \mathrm{v})$. This concentration was chosen to mimic expected steady-state concentrations of microbially produced butyraldehyde. Excellent product purity is observed for all catalysts after extraction of the aqueous media with $\mathrm{CH}_{2} \mathrm{Cl}_{2}$, except in the case of proline, which produced primarily aldol addition (not condensation) products. 
General procedure: A solution of $\beta$-alanine $(550 \mathrm{mM})$ in minimal media $(50 \mathrm{~mL})$ and aldehyde $(70 \mathrm{mM} ; 0.5 \% \mathrm{v} / \mathrm{v})$ was incubated with shaking at $37^{\circ} \mathrm{C}$ for $24 \mathrm{~h}$. The reaction was extracted with $\mathrm{CH}_{2} \mathrm{Cl}_{2}(3 \times 15 \mathrm{~mL})$, dried over $\mathrm{MgSO}_{4}$, and the solvent was removed by rotary evaporation. In the case of an emulsion, a saturated $\mathrm{NaCl}$ solution was added to the aqueous phase to resolve the emulsion and facilitate extraction.

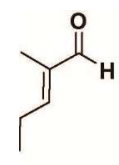

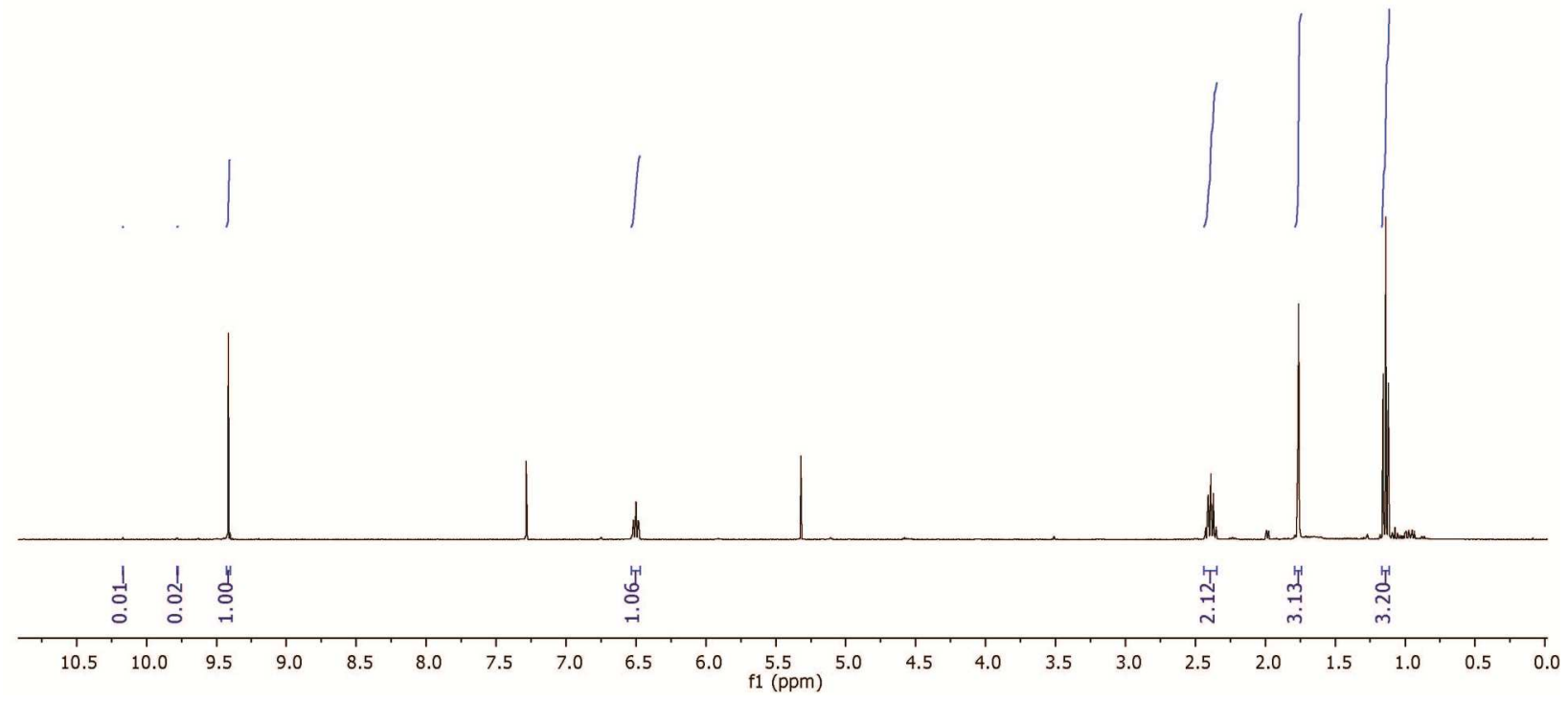

Figure S7. ${ }^{1} \mathrm{H}$ NMR spectrum of 2-methyl-pent-2-enal produced by $\beta$-alanine organocatalysis of n-propanal. 

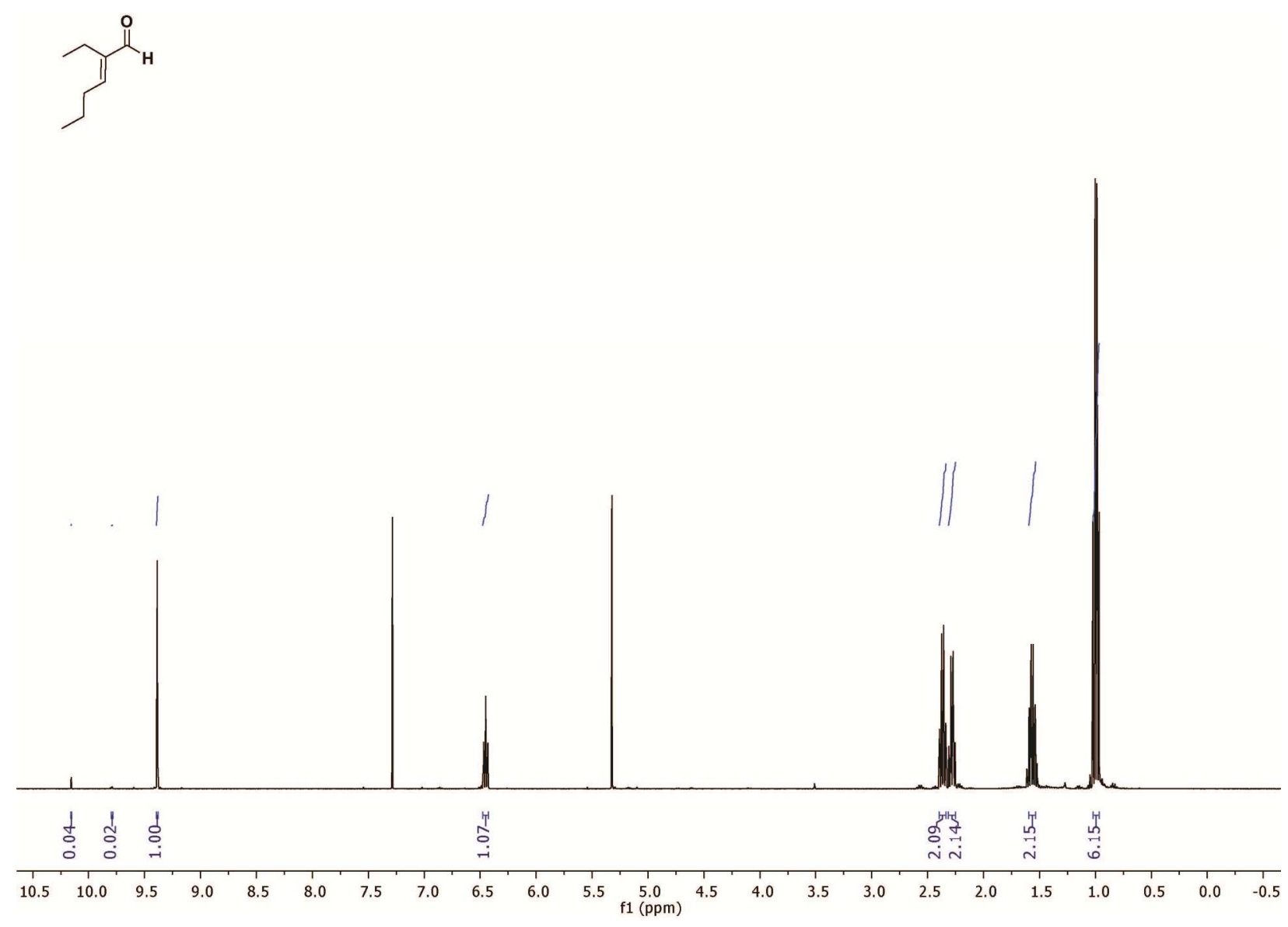

Figure S8. ${ }^{1} \mathrm{H}$ NMR spectrum of 2-ethyl-hex-2-enal produced by $\beta$-alanine organocatalysis of nbutanal. 

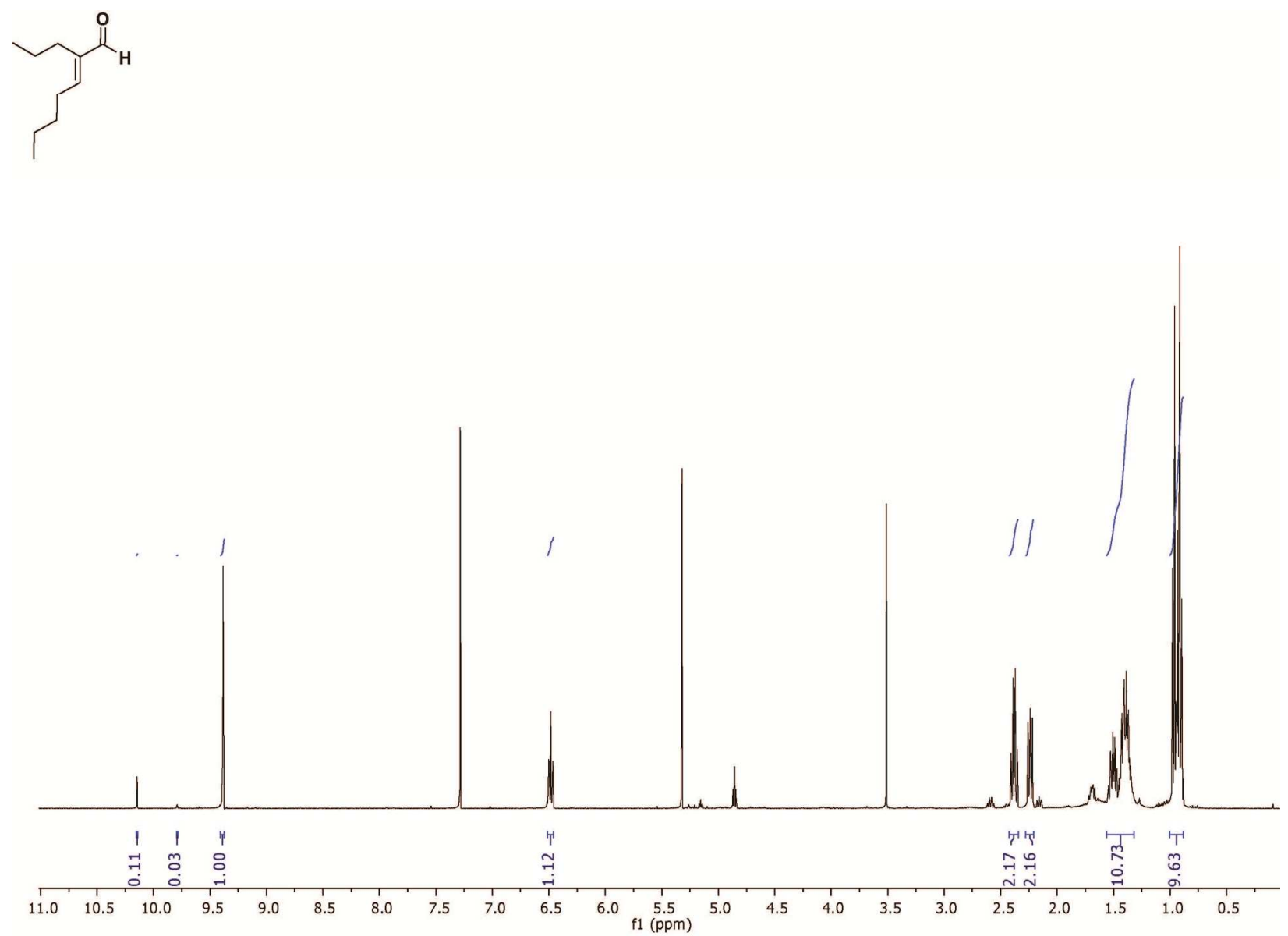

Figure S9. ${ }^{1} \mathrm{H}$ NMR spectrum of 2-propylhept-2-enal produced by $\beta$-alanine organocatalysis of n-pentanal. 


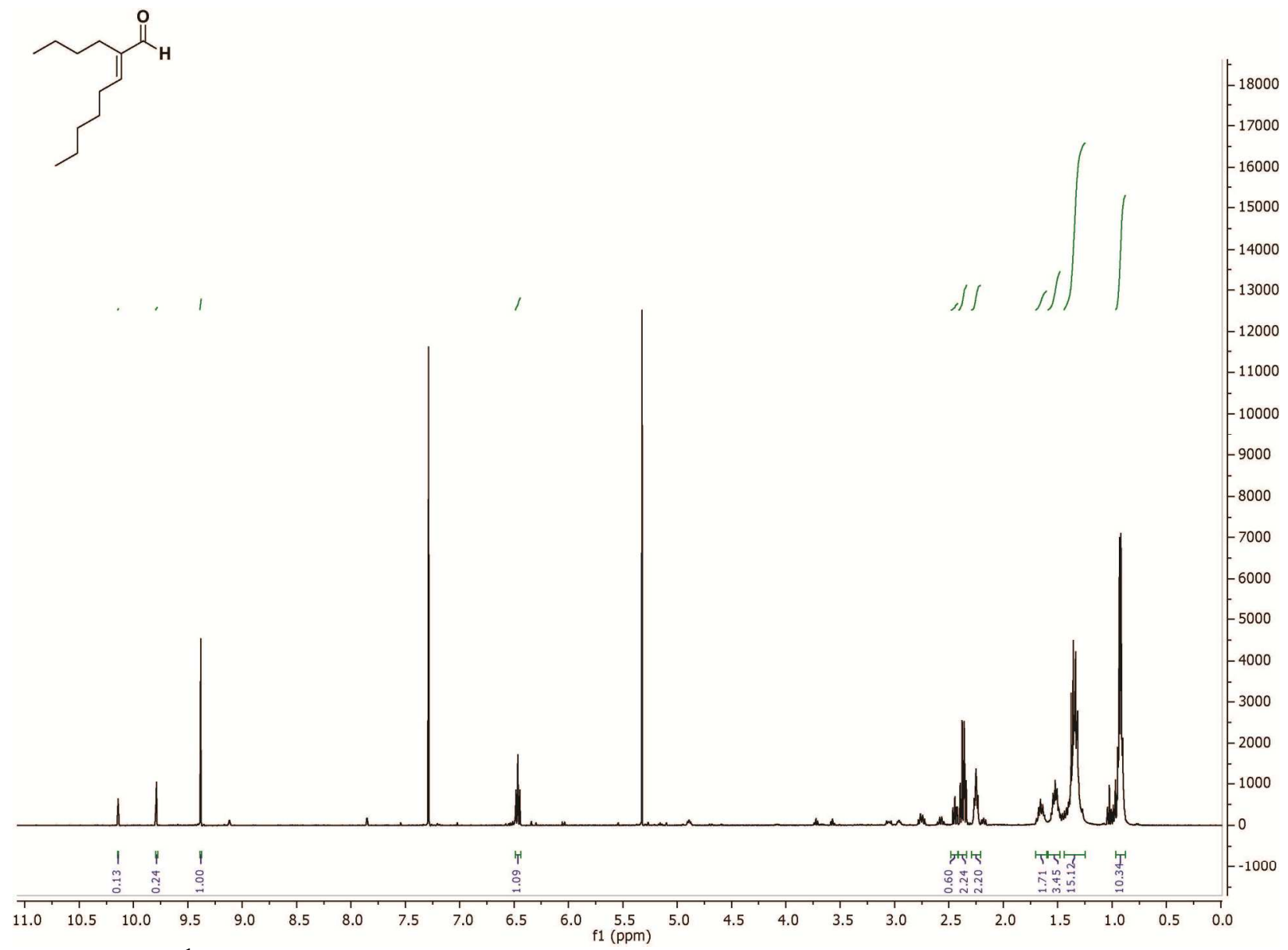

Figure S10. ${ }^{1} \mathrm{H}$ NMR spectrum of 2-butyloctyl-2-enal produced by $\beta$-alanine organocatalysis of n-hexanal. 


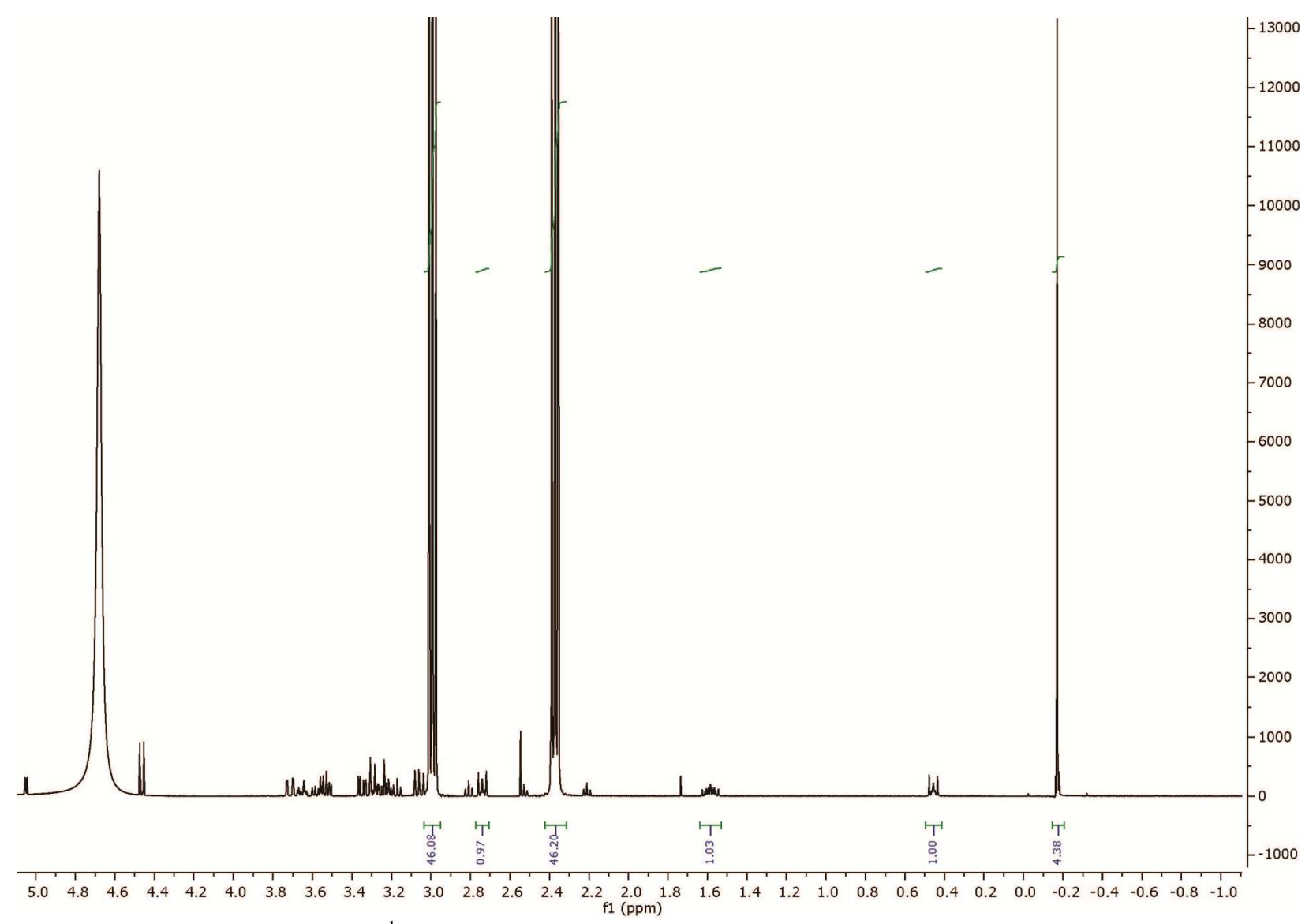

Figure S11. Representative ${ }^{1} \mathrm{H}$ NMR of $\beta$-alanine in minimal media with the DSS internal standard after E. coli growth for 24 h at $37^{\circ} \mathrm{C}$. 